\title{
Effect of Action Observational Training on Gait in People with Stroke
}

\author{
JongSu Lee', YoungMi Kim², DongKyu Lee ${ }^{3}$ \\ 1,3Department of Rehabilitation Science, Graduate school, Daegu University, Daegu; '2Department of Physical Therapy, Andong Science College, \\ Andong, Korea
}

Purpose: This study examined the effects of action observational training to improve the gait function for patients with stroke.

Methods: The participants were divided into two groups: right hemiplegia group $(n=12)$ and left hemiplegia group $(n=12)$. All groups received conventional therapy for five sessions for 30 minutes, each for three weeks. Left and right hemiplegia group practiced additional action observational training for five sessions for 20 minutes each for three weeks. They participated in three weeks of action observational training coupled with immediate physical practice (intervention), followed by a final assessment. The duration of each action observation video sequence was 10 minutes, followed immediately by practice of the observed motor skill (10 minutes). The gait velocity, cadence, swing time, step length, and BOS (base of support) were examined using the GAITRite system.

Results: The results of this study showed significant improvement in the gait function. The outcomes of the gait abilities from gait velocity, cadence, swing time, step length of the affected side, and BOS (base of support) were improved significantly in the right hemiplegia group $(p<0.05)$. In the left hemiplegia group, there was no significant improvement in the gait velocity, cadence, and BOS except for the swing time and step length of the affected side. The left and right group comparisons between the groups were not significant $(p<0.05)$. Conclusion: Action observation training improves the gait function. These results suggest that action observational training is feasible and suitable for stroke patients.

Keywords: Action observation, Gait, Stroke

\section{서 론}

뇌졸중 후 보행 능력의 손상은 환자가 기능적 독립을 이루는데 큰 장 애가 되고, 독립적으로 보행할 수 있는 능력은 일상생활에 참여하기 위한 선행조건이다. 뇌졸중 환자에게 특징적으로 나타나는 시공간 적 보행 양상은 한발짝률(cadence)의 감소, 보행 속도(gait velocity)의 감소, 한걸음 길이(stride length)의 감소와 한발짝 넓이(step width)의 증가, ${ }^{2}$ 양하지 지지기(double limb support stance)의 증가, 지구력 감소 및 보행 주변 환경에 대한 적응력 저하에 따른 보행의 질 저하이며, 마비측은 비마비측에 비해 짧은 디딤기와 상대적으로 긴 흔듦기가 나타난다. ${ }^{4}$ 이러한 보행 특성의 변화들은 뇌졸중 환자의 기능적인 보 행을 어렵게 만들고 시간적, 공간적, 운동학적, 운동역학적 보행의 비 칭성과 에너지 소모율의 증가 등을 만들어, ${ }^{5}$ 짧은 거리를 걸을 때에도

Received Sep 4, 2019 Revised Jan 6, 2020

Accepted Feb 5, 2020

Corresponding author YoungMi Kim

E-mail h1015m@naver.com
효율적인 보행 속도를 유지하기 어렵게 된다. ${ }^{6}$ 따라서 효과적인 보행 훈련은 뇌졸중 환자의 신경재활의 중요한 목표가 된다. 뇌졸중 환자 에게 있어 보행은 일상생활동작 증진과 독립적인 활동을 위해 가장 기본이 되는 기능인 점을 고려하였을 때 이를 극복하기 위한 재활 치 료적 전략은 매우 중요하다. 이러한 목적을 이루기 위하여 동작관찰 처럼 거울신경원에 기반을 둔 접근법들이 뇌졸중 재활의 보완책으 로 제안되고 있다. ${ }^{8}$

동작 관찰은 다른 사람이 수행하는 활동 또는 영상 속에 등장하 는 모델의 활동을 관찰하여 시각 및 청각 효과를 이용하여 대상자의 행동을 개선하기 위해 사용되는 접근 방법이다. 운동을 관찰하는 동 안 마치 자신이 그 동작을 하고 있다고 생각할 때 활성되는 피질 영역 과 피질하영역이 실제로 활동을 하는 동안 활성화되는 뇌 영역과 유 사하다고 보고 하였고, ${ }^{10}$ 최근의 신경생리학 외 이미지 연구들에서도
Copylight (C)2020 The Korean Society of Physical Therapy

This is an Open Access article distribute under the terms of the Creative Commons Attribution Non-commercial License (https:// creativecommons.org/license/by-nc/4.0.) which permits unrestricted non-commercial use, distribution, and reproduction in any medium, provided the original work is properly cited. 
동작 관찰 동안에도 과제의 실제수행에 관여하는 뇌 영역과 척수가 활성화되며, 해당 근육부위의 운동유발전위가 증가된다고 보고하였 다." 이러한 신경 네트워크의 변화가 자기공명상(fMRI)법과 경두개 자기자극(transcranial electromagnetic stimulation, TMS)법등을 통해 입증되고 있다.12

이러한 동작관찰 훈련을 파킨슨 환자에게 시켰을 때 보행 속도가 향상된다고 보고 하였고, ${ }^{13}$ 비디오를 이용한 시각 모델링의 관찰이 학 습자의 동작패턴을 모델과 유사하게 개선시키는 것으로 나타났다. ${ }^{14}$ 실제로 동작 관찰은 다양한 운동기능의 학습을 촉진시키고, ${ }^{15}$ 과제 수행 장면에 대한 구체적이고 선명한 자극을 제공함으로써 운동 심 상보다 효과적으로 운동 표상(motor representation)의 형성에 기여 할 수 있다고 하였다. ${ }^{16}$ 이전 연구에서 왼쪽 뇌는 움직임의 동적 측면을 최적화하고 예측하는 역할을 하고 오른쪽 뇌는 움직임의 정확성과 안정성을 담당한다고 보고하였고, ${ }^{17}$ 팔을 뻗는 동작에서 오른쪽 마 비 환자는 이동방향을 제어하는데 어려움을 겪는 반면 왼쪽 마비 환 자는 목표를 초과해서 달성하는 경향이 있다는 것을 보고하였다. ${ }^{18}$ 또한 우세측 오른쪽마비 환자들이 행동관찰 동안 더 큰 실행증을 보 인다는 것을 확인함으로써 운동조절 시스템에서 반구 특성화가 존 재한다는 것을 확인하였다. ${ }^{19}$ 하지만 선행된 연구들은 뇌졸중 환자 를 대상으로 동작관찰훈련을 통환 뇌 활동의 변화와 운동기억의 형 성, 상지 기능의 회복과 관련된 연구가 대부분 이었으며, 보행능력의 향상과 관련된 연구는 상대적으로 부족한 실정으로 마비부위에 따 른 효과를 비교한 연구는 거의 이루어지지 않았다. 따라서 본 연구는 동작관찰 훈련이 뇌졸중 환자의 마비부위에 따른 보행 능력 변화에 미치는 영향을 알아보고자 하였다.

\section{연구 방법}

\section{1. 연구대상}

본 연구는 뇌출혈이나 뇌경색으로 인한 뇌 손상이 발병한 지 6 개월 이상인 만성 뇌졸중 환자 30 명을 대상으로 실시하였다. 대상자는 오 른쪽 반신마비 환자군 15 명, 왼쪽 반신마비 환자군 15 명으로, 1) 보조 도구 사용 유무에 상관없이 $6 \mathrm{~m}$ 이상 독립 보행이 가능하고 수정된 운동평가 척도 보행 항목을 평가 하여 수준이 2이상인자, 2) 한국형 간이 정신상태검사(mini-mental status examination-korea, MMSE-K) 의 점수가 24 이상 인자로 인지 기능에 문제가 없으며, ${ }^{20} 3$ 3) 의사소통이 가능하고 다른 신경학적, 정형학적인 질환이 없는 자, 4) 시야 결손과 전정기관에 이상이 없는 자, 5) 본 연구의 목적을 이해하고 실험에 참 여하는 것을 동의한 자로 하였다.본 실험은 2012년 9월 17일부터 10월 12 일까지 약 15 회 실시하였다.

\section{2. 실험방법}

1) 측정도구

(1) GAITRite system

보행의 시·공간 변수를 분석하기 위하여 GAITRite system을 사용하 였다. 수집된 시·공간 변수에 대한 정보는 GAITRite GOLD, Version $3.2 \mathrm{~b}$ 소프트웨어로 처리하였다. 평가는 대상자를 보행 $2 \mathrm{~m}$ 앞에 서 있 도록 한 다음, 검사자의 구두신호에 따라 가장 편안한 보행속도로 길 이 $461 \mathrm{~cm}$, 폭 $88 \mathrm{~cm}$ 의 보행매트를 걸어가는 방식으로 측정 하였으며 3 회 측정한 후 평균값을 사용하였다. 편안한 속도에서의 측정자 내 신뢰도는 $r=0.92$ 이고, 다른 보행 평가 도구와의 타당도에서도 높은 수준을 나타내었다.21,22

\section{2) 연구절차}

본 연구는 사전-사후 검사 대조군 설계(pre -post test control group design)로 구성 하였다. 연구 집단은 중재 방법에 따라 뇌졸중으로 인한 오른쪽 반신마비 15 명과 왼쪽 반신마비 15 명을 무작위로 선출하였 다. 본 연구 대상자 30 명 중 GAITRite측정 과정에서 보행 양상이 뚜렷 하지 않아 측정이 어려운 대상자 2 명이 제외 되었으며 훈련기간 타 병 원으로 전원한 대상자 3 명과 개인사유에 의해 1 명의 대상자가 탈락 하여 3 주간의 훈련을 마치고 사후 평가까지 완수한 대상자는 24 명 이 였다. 따라서, 최종적으로 연구에 참여한 대상자는 오른쪽 반신마비 환자 12 명, 왼쪽 반신마비 환자 12 명이었다. 두 그룹간의 마비 부위에 대한 보행의 차이를 알아보기 위하여 오른쪽 반신마비만을 위한 동 영상을 제작하여 관찰하게 하였다. 본 연구에 참여한 대상자의 연령, 성별, 발병일, 손상부위 등은 의무 기록지에서 확인하였으며, 훈련 보 행 변인을 측정하기 하여 GAITRite를 통해 시. 공간적인 보행 변수를 평가하였다. 대상자들은 공통으로 하루 30 분씩 일반적인 물리치료 를 받았고 일반적인 물리치료에는 신경근 발달 치료와 근력강화 운 동, 가동범위 증진 운동 및 기능 훈련이 포함 되었다. 훈련 프로그램 은 주 5 회 3 주간 실시하였으며 실험군과 대조군 모두 오른쪽 반신마 비용 동영상을 통한 동작관찰 훈련을 20 분씩 실시하였다. 중재 후 대 상자들의 보행능력의 사후 검사를 실시하였으며 모든 평가는 총 3 회 실시 하였고 그 평균값을 제시 하였다

\section{3) 중재방법}

(1) 동작관찰훈련(action observational training)

본 연구에서는 보행 훈련에 중점을 둔 동작 관찰 훈련을 시행하였다. 대상자가 집중을 잘 할 수 있도록 외부인의 출입이 제한된 조용한 방 에서 편안하게 의자에 앉아 미리 녹화된 동영상을 주 5 회 시청하였 다. 오른쪽 반신마비군과 왼쪽 반신마비군에서 그룹간의 보행 능력 의 차이를 비교하기 위하여 오른쪽 반신마비만을 한 동영상을 정상 


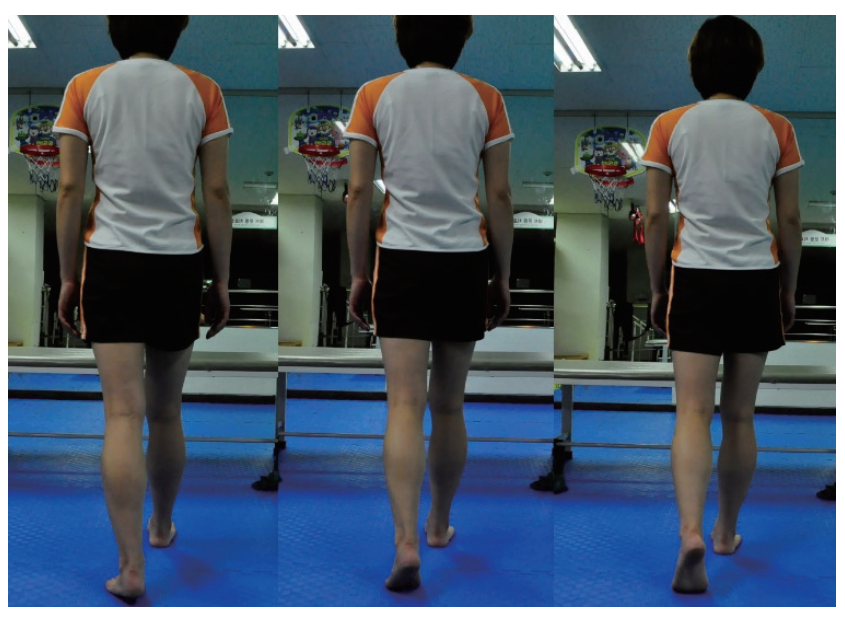

Figure 1. Action Observation training grade 1

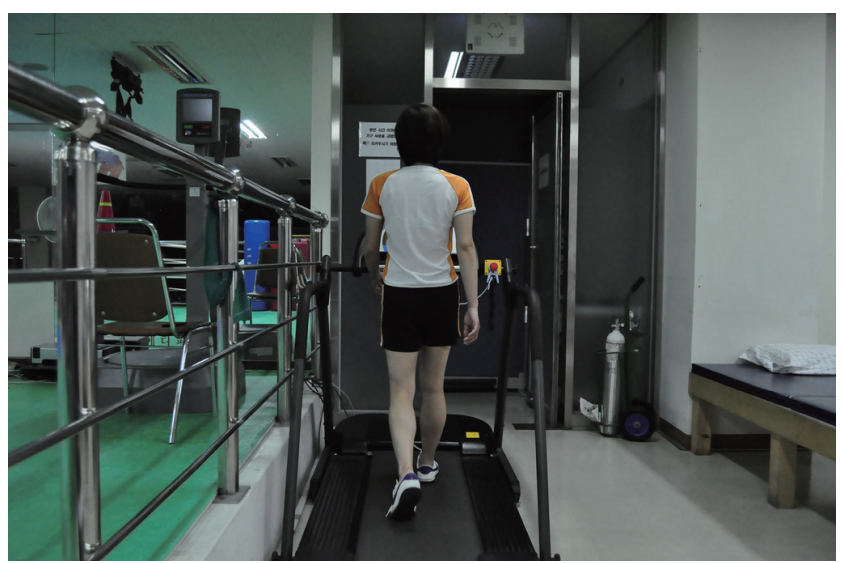

Figure 2. Action Observation training grade 2

인을 대상으로 제작 하였으며 대상자의 학습에서 좌우 대칭의 교란 을 막기 위하여 후방의 동영상을 제공하였다. 훈련프로그램은 Kim 과 Lee ${ }^{23}$ 의 동작관찰훈련 프로그램을 수정하여 난이도에 따라 3 단계 로 구성하였다. 1단계는 골반의 움직임을 위한 앉고 일어서기 동작과 좌우로 체중이동하기 동작으로 구성하였고(Figure 1), 2단계는 보행 훈련을 위한 등속성의 트레드밀 보행으로 구성 하였으며(Figure 2), 3 단계는 기능적 보행훈련을 위해 난이도와 복잡성이 증가된 장애물 보행과 계단 보행으로 구성되었다(Figure 3). 두 군 모두 동영상 시청 시간은 10 분이며 시청하는 동안 대상자들이 동영상 내용을 따라 하 거나 움직이지 않게 하였다. 또한 동작을 이해하고 동작관찰에 집중 할 수 있도록 치료사가 독려 하였으며 동작관찰 훈련의 효과를 높이 기 위해 시청 후 동영상 내용과 같은 신체훈련을 10 분간 치료사와 함 께 실시하였다.

\section{4) 자료분석}

본 연구에서의 통계처리는 연구의 목적을 위해 수집된 자료를 IBM

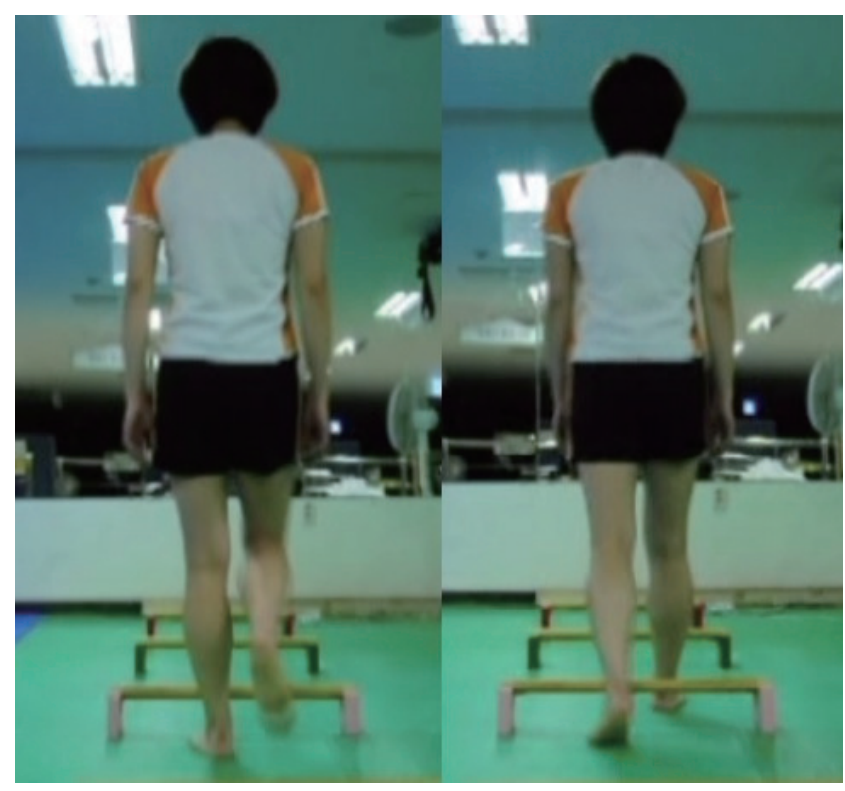

Figure 3. Action Observation training grade 3

SPSS Statistics 20.0 KO (IBM, IL, USA) 통계프로그램을 이용하였다. 대 상자의 일반적 특성은 기술통계로 분석하였으며, 그룹 내 중재 전후 차이 검증을 위하여 대응표본 $\mathrm{t}$-검정을 실시하였다. 오른쪽 반신마비 군과 왼쪽 반신마비군의 실험 전 차이를 분석하기 위해 독립표본 $\mathrm{t}$ 검 정을 사용하여 두 그룹간 차이가 없음을 확인하였다. 두 그룹간의 중 재 후 차이를 비교하기 위하여 시간과 그룹간에 상호작용이 존재하지 않는 흔듦기(swing time)과 한발짝 길이(step length)는 공분산 분석을 실시하였고, 시간과 그룹간에 상호작용이 존재하는 보행 속도 (gait velocity), 한발짝률(cadence), BOS(base of support) 는 이요인 반복측정 분 산분석을 실시하였다. 통계학적 유의 수준은 0.05 로 설정하였다.

\section{결 과}

\section{1. 대상자의 일반적 특성}

본 연구에 참여한 대상자는 뇌졸중으로 진단받은 환자 총 24 명으로 오른쪽 반신마비군 12 명, 왼쪽 반신마비군 12 명으로 하였다. 그룹별 신체적 특성과 변수별 측정 자료는 평균 및 표준편차를 산출하였고, 자료의 정규성 검정은 Shapiro-Wilk 검정을 통해 확인했다. 오른쪽 반 신마비군과 왼쪽 반신마비군의 실험전 차이를 분석하기 위해 독립표 본 $\mathrm{t}$ 검정을 사용하여 확인하였다. 각 그룹별 연령, 신장, 체중 등에서 통계학적으로 유의한 차이가 없었고, 연구 대상자의 일반적 특성은 다음과 같다( $\mathrm{p}>0.05)$ (Table 1).

\section{2. 보행 변수}

보행 속도(gait velocity), 한발짝률(cadence), BOS (base of support)에서 
오른쪽 반신마비군에서는 유의한 차이를 보였고 $(\mathrm{p}<0.05)$, 왼쪽 반신 마비군은 유의한 차이를 보이지 않았다( $\mathrm{p}>0.05)$. 오른쪽 반신마비군 과 왼쪽 반신마비군의 3 주 훈련 후 두 그룹 간 측정 결과값은 그룹간 유의한차이가 없었다( $\mathrm{p}>0.05)$ (Table 2).

흔듦기(swing time), 한발짝 길이(step length of affected side)에서 두 군 모두 유의한 차이를 보였다 $(\mathrm{p}<0.05)$. 오른쪽 반신마비군과 왼쪽 반신마비군의 3 주 훈련 후 두 그룹 간 측정 결과 값은 그룹간 유의한 차이가 없었다 $(\mathrm{p}>0.05)($ Table 2).

\section{고 찰}

본 연구에서는 대상자의 마비 부위에 따라 두 군으로 나누어 동작관 찰훈련에 따른 보행능력의 변화를 알아보았다.

Table 1. General characteristics of subjects.

\begin{tabular}{lccc}
\hline & Rt group & Lt group & $\mathrm{p}$ \\
\hline $\mathrm{n}$ & 12 & 12 & \\
Sex (M/F) & $7 / 5$ & $8 / 4$ & \\
Age (years) & $55.33 \pm 10.267$ & $59.78 \pm 10.054$ & 0.387 \\
Height $(\mathrm{cm})$ & $164.08 \pm 8.808$ & $164.75 \pm 8.092$ & 0.363 \\
Weight $(\mathrm{kg})$ & $65.49 \pm 11.421$ & $62.44 \pm 9.643$ & 0.616 \\
Infarction & 8 & 7 & \\
Hemorrhage & 4 & 5 & \\
On set & $18.58 \pm 8.05$ & $20.92 \pm 9.10$ & 0.463 \\
MMSE-K & $27.33 \pm 3.39$ & $28.41 \pm 2.71$ & 0.432 \\
\hline
\end{tabular}

Mean \pm SD: mean \pm standard deviation, MMSE-K: mini-mental status examination-korea, ${ }^{*} p<0.05$.
본 연구결과 오른쪽 반신마비군의 보행 속도(gait velocity)와 한발 짝률(cadence)은 유의하게 증가한 반면에, 왼쪽 반신마비군의 보행 속 도와 한발짝률은 유의한 차이를 보이지 않았다. 본 연구결과 오른쪽 반신마비군의 보행 속도(gait velocity)와 한발짝률(cadence)은 유의하 게 증가한 반면에, 왼쪽 반신마비군의 보행 속도와 한발짝률은 유의 한 차이를 보이지 않았다. 만성 뇌졸중 환자를 대상으로 전체 이중과 제 동작관찰 신체 훈련을 한 선행 연구에서 훈련 전보다 훈련 후에 동 적보행지표 점수가 유의하게 증가 하였다. ${ }^{24} 14$ 가지 기능적 보행 과제 인 오른쪽 및 왼쪽으로 고개 돌리며 걷기, 시계방향 및 반시계 방향으 로 돌기, 장애물 돌아가기, 장애물 넘기 등으로 이루어진 동작 관찰 연구에서 동작관찰 신체훈련군 에서 훈련 전보다 훈련 후 보행의 기 능적 과제 수행 능력에 유의하게 증가되었다. ${ }^{25}$ 또한 앉고 일어서 걷기 보행 과제로 이루어진 동작관찰연구의 실험군에서 동적보행지표 점 수가 훈련 전보다 훈련 후에 유의하게 증가되어 본 연구와 유사한 결 과가 나타났다. ${ }^{26}$

한발짝길이(step length of affected side)에서는 두 군 모두 유의한 증 가를 보였다. ${ }^{24}$ 뇌졸중 환자를 대상으로 6주간 운동심상과 동작관찰 훈련을 실시한 연구에서도 마비측의 한발짝 길이가 훈련 후 유의하 게 증가하였다고 보고하였다. ${ }^{27} 21$ 명의 뇌졸중 환자를 대상으로 실험 군은 보행 동작을 관찰하고 대조군은 풍경을 관찰한 연구에서 실험 군은 흔듦기, 디딤기, 한발짝 길이에서 유의한 변화가 있었다. 본 연구 에서도 두 군 모두 흔듦기와 한발짝 길이에서 유의한 증가가 있었다. ${ }^{28}$ 22 명의 뇌졸중 환자를 대상으로 실험군은 동작관찰훈련을, 대조군 은 일반적인 보행훈련을 실시한 연구에서도 본 연구와 유사한 결과 가 나타났다. 실험군은 한발짝률, 보행 속도, 한발짝 길이, 한걸음 길

Table 2. The results of Gait parameters on each groups at pre-post intervention

\begin{tabular}{|c|c|c|c|c|c|c|}
\hline \multirow{2}{*}{ Group } & \multicolumn{2}{|c|}{ Rt group } & \multicolumn{2}{|c|}{ Lt group } & \multirow{2}{*}{$f$} & \multirow{2}{*}{$\mathrm{p}$} \\
\hline & pre-test & post-test & pre-test & post-test & & \\
\hline Velocity $(\mathrm{cm} / \mathrm{s})$ & $30.99 \pm 16.48$ & $42.13 \pm 17.79$ & $36.13 \pm 15.77$ & $41.83 \pm 13.85$ & 1.764 & 0.198 \\
\hline $\mathrm{t}$ & \multicolumn{2}{|c|}{-12.033} & \multicolumn{2}{|c|}{-1.43} & & \\
\hline $\mathrm{p}$ & \multicolumn{2}{|c|}{$0.00^{*}$} & \multicolumn{2}{|c|}{0.18} & & \\
\hline Cadence (step/min) & $70.46 \pm 25.41$ & $76.13 \pm 25.33$ & $72.46 \pm 22.12$ & $74.04 \pm 24.58$ & 0.602 & 0.446 \\
\hline $\mathrm{t}$ & \multicolumn{2}{|c|}{-2.691} & \multicolumn{2}{|c|}{0.205} & & \\
\hline $\mathrm{p}$ & \multicolumn{2}{|c|}{$0.021^{*}$} & \multicolumn{2}{|c|}{0.841} & & \\
\hline $\mathrm{BOS}(\mathrm{cm})$ & $19.00 \pm 4.14$ & $15.42 \pm 3.94$ & $19.08 \pm 4.37$ & $18.42 \pm 4.61$ & 1.637 & 0.214 \\
\hline $\mathrm{t}$ & \multicolumn{2}{|c|}{4.743} & \multicolumn{2}{|c|}{0.303} & & \\
\hline $\mathrm{p}$ & \multicolumn{2}{|c|}{$0.001^{*}$} & \multicolumn{2}{|c|}{0.768} & & \\
\hline Swing time $(\mathrm{cm})$ & $0.47 \pm 0.20$ & $0.65 \pm 0.23$ & $0.49 \pm 0.12$ & $0.55 \pm 0.13$ & 2.136 & 0.159 \\
\hline $\mathrm{t}$ & \multicolumn{2}{|c|}{-2.37} & \multicolumn{2}{|c|}{-2.544} & & \\
\hline $\mathrm{p}$ & \multicolumn{2}{|c|}{$0.037^{*}$} & \multicolumn{2}{|c|}{$0.027^{*}$} & & \\
\hline Step length (cm) & $25.08 \pm 11.63$ & $31.67 \pm 7.86$ & $28.03 \pm 9.54$ & $32.49 \pm 7.84$ & 0.479 & 0.497 \\
\hline $\mathrm{t}$ & \multicolumn{2}{|c|}{-4.011} & \multicolumn{2}{|c|}{-3.232} & & \\
\hline $\mathrm{p}$ & \multicolumn{2}{|c|}{$0.002^{*}$} & \multicolumn{2}{|c|}{$0.008^{*}$} & & \\
\hline
\end{tabular}

Mean \pm SD: mean \pm standard deviation, BOS: base of support, ${ }^{*} p<0.05$ 
이, 단하지 지지기, 양하지 지지기에서 유의한 차이를 보였지만, 대조 군은 한걸음길이에서만 유의한 차이가 나타났다. ${ }^{29}$

보행을 분석한 선행 연구들에서 보행이 불안정한 경우에 한걸음 길이가 감소하고, ${ }^{30}$ 보행속도가 $0.33 \mathrm{~m} / \mathrm{s}$ 이상부터는 보행 속도와 분 속수 사이의 높은 상관관계가 있으며, 보행 속도가 빠를수록 보행 주 기가 좋아지고 한발짝 길이가 증가하면서 보행의 대칭성이 증가한다 고 하였다. ${ }^{31}$ 또한 마비 측의 한발짝 길이와 한걸음 길이의 증가는 보 행 속도 및 균형을 증가시키는 직접적 원인이라고 보고하였다. ${ }^{32}$ 본 연 구에서 동작관찰 훈련 후 보행안정성이 증가하면서 오른쪽 반신마비 군은 마비측의 한발짝 길이가 증가되고 보행 속도, 한발짝률, 흔듦기, $\mathrm{BOS}$ 에서 유의한 향상이 나타난 것으로 사료된다. 또한 양 발의 지지 면(BOS)이 좁아지고 한발짝 길이를 증가시켜 비마비측에서 단하지 지지 시간을 단축시키고 한걸음 길이를 증가시킴으로 양 하지 상호 조절작용의 증진에 의해 근골격계의 생역학적인 기전의 개선과 양 하지의 비대칭성이 감소되었을 것이라 사료된다. 이러한 결과는 훈련 과제를 학습하는 과정에서 동영상 관찰을 통해 유도된 시각적인 활 성이 움직임에 대한 상세한 정보를 제공하였고, ${ }^{33}$ 과제에 대한 정보와 그에 대한 이해가 신체훈련을 통해 더 향상된 기능적 결과를 얻은 것 으로 보인다. ${ }^{34}$

본 연구에서 적용된 동작관찰훈련 프로그램은 좌우측으로 체중 이동하기, 트레드밀 보행하기, 앉았다 일어서기, 보행 중 장애물 넘기 등으로 구성하였는데, 이는 환자로 하여금 뇌졸중 발병 후 경험해 보 지 못한 마비측으로의 전후, 좌우 방향의 체중이동 동작에 대한 이해 를 높여주는 효과를 가져와 대칭적인 체중지지 양상의 회복을 도모 하고, 보행 장애물 넘기 동작과 같은 과제지향 움직임을 통해 운동영 역의 활성을 더 촉진하였을 것이라고 생각된다. 또한 손상 받기 이전 에 수행하던 동작을 다시 관찰하고, 모방하는 과정을 거쳐 수행하게 됨으로써 마비측의 기능 수행에 긍정적인 결과를 가져올 수 있었을 것으로 사료된다.

비록 그룹 간에 유의한 차이는 나타나지 않았지만 오른쪽 반신마 비군에서 모든 보행 변수가 유의하게 나타난 것에 비해, 왼쪽 반신마 비군에서는 흔듦기와 한발짝 길이만 유의하게 나타나, 동영상 제작 시 마비측에 맞춰서 제작하는 것이 바람직할 것으로 사료된다. 본 연 구는 많은 수의 대상자를 포함시키지 못하였고 상대적으로 짧은 연 구 기간으로 인해 연구 결과를 일반화하기에는 제한이 따르며, 치료 시간외에 각 개인마다 이뤄지는 자발적인 운동을 통제하지 못하였 다. 이러한 제한에도 불구하고 본 연구는 동일한 신체훈련조건의 대 상자들을 왼쪽 반신마비군과 오른쪽 반신마비군으로 나누어 동작 관찰을 결합하여 훈련하였고 보행능력을 증진시키는 결과를 나타냄 으로써 동작관찰훈련의 효과를 입증하였다고 본다.

본 연구와 선행연구들의 결과를 볼 때 거울신경원의 특성을 고려
한 동작관찰훈련을 일반적인 물리치료 중재법과 병행하여 뇌졸중 환자의 운동 회복을 위한 중재 방법으로 사용하게 된다면 운동능력 이 저하된 반신마비 환자들에게 추가적인 치료 효과를 얻을 수 있을 것이라 사료된다. 여러 선행 연구들과 본 연구의 결과를 바탕으로 앞 으로 진행될 연구에서는 좀 더 많은 환자들을 대상으로 개인의 특성 을 고려하여 개인에게 의미 있는 동작을 파악해 개개인에게 맞춰진 자극과 움직임들로 구성된 동작관찰 훈련을 진행하는 연구가 이루 어져야할 것이다.

\section{REFERENCES}

1. Jackson PL, Doyon J, Richards CL et al. The efficacy of combined physi$\mathrm{cal}$ and mental practice in the learning of a foot-sequence task after stroke: A case report. Neurorehabil Neural Repair. 2004;18(2):106-11.

2. PatlaElble RJ, Thomas SS, Higgins C et al. Stride-dependent changes in gait of older people. J Neurol. 1991;238(1):1-5.

3. Dean CM, Richards CL, Malouin F. Walking speed over 10 metres overestimates locomotor capacity after stroke. Clin Rehabil. 2001;15(4):41521.

4. Bogey RA, Barnes LA, Perry J. Computer algorithms to characterize individual subject emg profiles during gait. Arch Phys Med Rehabil. 1992;73(9):835-41.

5. Kim CM, Eng JJ. The relationship of lower-extremity muscle torque to locomotor performance in people with stroke. Phys Ther. 2003;83(1): 49-57.

6. Eng JJ, Winter DA, Patla AE. Strategies for recovery from a trip in early and late swing during human walking. Exp Brain Res. 1994;102(2):33949.

7. Tong RK, Ng MF, Li LS. Effectiveness of gait training using an electromechanical gait trainer, with and without functional electric stimulation, in subacute stroke: A randomized controlled trial. Arch Phys Med Rehabil. 2006;87(10):1298-304.

8. Garrison KA, Winstein CJ, Aziz-Zadeh L. The mirror neuron system: A neural substrate for methods in stroke rehabilitation. Neurorehabil Neural Repair. 2010;24(5):404-12.

9. Mulder T, Hochstenbach JB, van Heuvelen MJ et al. Motor imagery: the relation between age and imagery capacity. Hum Mov Sci. 2007;26(2): 203-11.

10. Decety J, Perani D, Jeannerod M et al. Mapping motor representations with positron emission tomography. Nature. 1994;371(6498):600-2.

11. Filimon F, Nelson JD, Hagler DJ et al. Human cortical representations for reaching: mirror neurons for execution, observation, and imagery. Neuroimage. 2007;37(4):1315-28.

12. Levy CE, Nichols DS, Schmalbrock PM et al. Functional mri evidence of cortical reorganization in upper-limb stroke hemiplegia treated with constraint-induced movement therapy. Am J Phys Med Rehabil. 2001; 80(1):4-12.

13. Pelosin E, Avanzino L, Bove M et al. Action observation improves freezing of gait in patients with parkinson's disease. Neurorehabil Neural Repair. 2010;24(8):746-52.

14. Horn RR, Williams AM, Scott MA. Learning from demonstrations: the 
role of visual search during observational learning from video and pointlight models. J Sports Sci. 2002;20(3):253-69.

15. Williams JH, Whiten A, Suddendorf T et al. Imitation, mirror neurons and autism. Neurosci Biobehav Rev. 2001;25(4):287-95.

16. Kim JH, Chung EJ, Lee BH. A study of analysis of the brain wave with respected to action observation and motor imagery: a pilot randomized controlled trial. J Phys Ther Sci. 2013;25(7):779-82.

17. Vivek Y, Robert LS. Limb dominance results from asymmetries in predictive and impedance control mechanisms. PLOS One. 2014; vol.9(4) article e 93892

18. Saandeep M, Pratik KM, Andrzej P et al. Contralesional motor deficits after unilateral stroke reflect hemisphere-specific control mechanisms. Brain. 2013;136(4):1288-303.

19. Kathleen AG, Lisa AZ, Savio WW et al. Modulating the motor system by action observation after stroke. Stroke. 2013 ;44(8): 2247-2253.

20. Folstein MF, Folstein SE, McHugh PR. "Mini-mental state". A practical method for grading the cognitive state of patients for the clinician. J Psychiatr Res. 1975;12(3):189-98.

21. McDonough AL, Batavia M, Chen FC et al. The validity and reliability of the gaitrite system's measurements: A preliminary evaluation. Arch Phys Med Rehabil. 2001;82(3):419-25.

22. van Uden CJ, Besser MP. Test-retest reliability of temporal and spatial gait characteristics measured with an instrumented walkway system (gaitrite). BMC Musculoskelet Disord. 2004;5:13.

23. Kim JH, Lee BH. Action observation training for functional activities after stroke: a pilot

randomized controlled trial. NeuroRehabilitation. 2013;33(4):565-74.

24. Lee HM, Lee JA. The effects of dual-task action observation physical training on the walking ability and activities of daily living in chronic stroke patients. J Korean Soc Phys Med. 2016;11(2):83-91.

25. Park H-R, Kim J-M, Lee M-K et al. Clinical feasibility of action observation training for walking function of patients with post-stroke hemiparesis: A randomized controlled trial. Clinical rehabilitation. 2014; 28(8):794-803.

26. Kim J-C, Lee H-M. The effect of action observation training on sit to walk with chronic stroke patients. The Journal of Korean Physical Therapy. 2015;27(6):413-8.

27. Kim JS. The effect of action observation on gait in hemiparesis patients. Journal of the Korea Academia-Industrial cooperation Society. 2012; 13(8):3610-7

28. Park HR, Kim JM, Lee MK et al. Clinical feasibility of action observation training for walking function of patients with post-stroke hemiparesis: A randomized controlled trial. Clin Rehabil. 2014;28(8):794-803.

29. Kang KY. Effects of observed action gait training on spatio-temporal parameter and motivation of rehabilitation in stroke patients. J Korean Soc Phys Med. 2013;8(3):351-60.

30. Halliday SE, Winter DA, Frank JS et al. The initiation of gait in young, elderly, and parkinson's disease subjects. Gait Posture. 1998;8(1):8-14.

31. Lamontagne A, Fung J. Faster is better: Implications for speed-intensive gait training after stroke. Stroke. 2004;35(11):2543-8.

32. de Quervain IAK, Simon SR, Leurgans S et al. Gait pattern in the early recovery period after stroke. JBJS. 1996;78(10):1506-14.

33. Kim TH, Park SB. Changes in the electroencephalogram patterns during motor imagery and action observation of elbow flexion and extension. Journal of Sport and Leisure Studies. 2007;31(11):987-99.

34. Yang YP, Kim SJ. The Effect of Action Observation with Observation Type on Limits of Stability and Dynamic Gait Ability in Stroke Patients. J Korean Soc Phys Med. 2017;12(1):67-74. 